\title{
Development of Lightweight Aluminum-Titanium Alloys for Aerospace Applications
}

\author{
SYEDA Ammara Batool ${ }^{1, a,{ }^{,},}$AKHLAQ Ahmad ${ }^{2, b}$, ABDUL Wadood $^{1, \mathrm{c}}$, \\ ABDUL Mateen ${ }^{1, d}$ and SYED Wilayat Hussain ${ }^{1, e}$ \\ ${ }^{1}$ Department of Materials Science and Engineering (MS\&E) Institute of Space Technology, near \\ Rawat Toll Plaza, Islamabad Pakistan \\ ${ }^{2}$ Department of Metallurgical \& Materials Engineering University of Engineering \& Technology, \\ Lahore Pakistan \\ a*syedaammara001@gmail.com, bdrakhlaq@uet.edu.pk, 'abdul.wadood@ist.edu.pk, \\ a.mateen@ist.edu.pk, ewilayat.hussain@ist.edu.pk
}

Keywords: Al-Ti System, Light Weight Alloys, Powder Metallurgy, Aerospace.

\begin{abstract}
Aluminum (Al) and Titanium (Ti) based lightweight alloys have been a topic of discussion and research for a few decades now. Resulting alloys with hard intermetallic phases in Al-Ti binary system have good microstructural and mechanical properties including low densities, high specific strength, better resistance against oxidation and corrosion which are highly desirable in aerospace industry. Such an alloy system was studied in our research. Powder metallurgy (PM) was used as processing route because of its economical and easy operation. Samples were prepared using metallic powders of Aluminum (Al) and Titanium (Ti) with varying compositions of 95 at.\% $\mathrm{Al}-\mathrm{Ti}, 90$ at.\% $\mathrm{Al}-\mathrm{Ti}$ and 88 at.\% Al-10 at.\% Ti-2 at.\% SiC. After compaction, pressureless sintering was carried out at $620{ }^{\circ} \mathrm{C}$ for several hours in Argon atmosphere followed by annealing resulting in a reasonably dense Al-Ti alloy. Microstructure and phase composition of alloy was analyzed by Scanning electron microscopy (SEM) and Energy dispersive spectroscopy (EDS), respectively. Hardness was evaluated by Vickers micro indentation test. An increase in hardness was observed. Sample containing reinforcement particles $(\mathrm{SiC})$ demonstrated highest value of hardness.
\end{abstract}

\section{Introduction}

Lightweight and strong materials have wide range of applications in transportation especially in air trafficking, sports industry and as biomaterial. Among many other materials, aluminum $\left(\mathrm{Al} 2.7 \mathrm{~g} / \mathrm{cm}^{3}\right.$ ) and titanium $\left(\mathrm{Ti} 4.5 \mathrm{~g} / \mathrm{cm}^{3}\right.$ ) have low densities that fulfill the basic light weight and high specific strength requirement of aerospace industry [1].

In Al-Ti binary alloy system various types of intermetallics (i.e. $\mathrm{Ti}_{3} \mathrm{Al}, \mathrm{TiAl}, \mathrm{TiAl}_{2}, \mathrm{TiAl}_{3}$, $\mathrm{Ti}_{2} \mathrm{Al}_{5}$ etc.) are produced [Fig. 1] at varying composition of $\mathrm{Al}$ with different crystal structure and enhanced mechanical properties as compared to their constituent elements [2]. Intermetallic based alloys have lower densities, high corrosion and creep resistance at elevated temperatures which is suitable for high temperature structural applications [3-5]. Such attractive properties make these alloys good replacement for conventional Ti and Ni based super alloys [6, 7]. With ever increasing demand of lighter and stronger frame structure of air vehicles and high temperature bearing parts of engines, Ti-Al based alloys are given much attention in recent works[8-11]. Powder metallurgy (PM) is a commonly used method for processing Al-Ti alloys due to the ease of operation and lower costs as compared to ingot metallurgy [12-14]. PM produces near-net shape parts that avoid difficulties and expenses of post-machining of rather brittle and stiff intermetallics.

In our study, four samples were prepared with varying proportions of $\mathrm{Al}$ and $\mathrm{Ti}$, with and without addition of ceramic reinforcements $(\mathrm{SiC})$. Alloy formed showed increment in hardness values with the addition of $\mathrm{Ti}$ in $\mathrm{Al}$. Resulting microstructures and properties are discussed in results section in detail. 


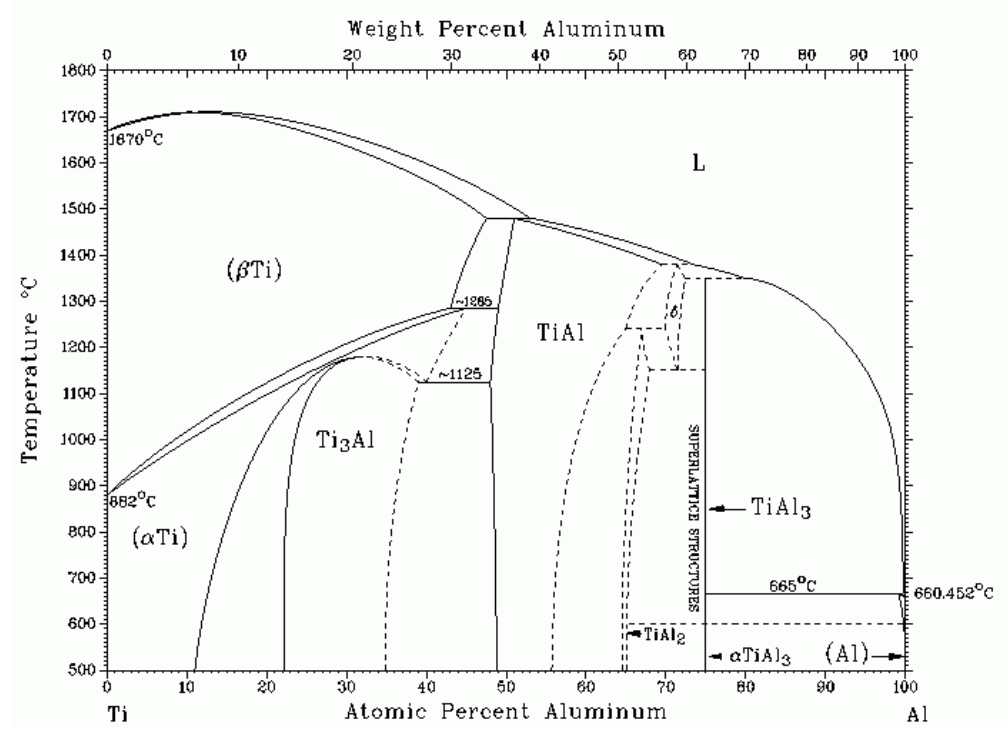

Fig. 1 Phase Diagram of Al-Ti binary system [15].

\section{Experimental Procedures}

Particle sizes of powders i.e. pure $\mathrm{Al}, \mathrm{Ti}$ and $\mathrm{SiC}$ were analyzed using a Laser diffraction particle size analyzer (Mastersizer 3000, Malvern Instrument, UK). Powder morphology was evaluated using Scanning electron microscope (TESCAN, MIRA-3, FEG-SEM, Czech Republic). Powders were mixed in ethanol and sonicated in an Ultra-sonicator (Hielscer UP400S, Germany) for $20 \mathrm{~min}$ prior to pressing. Different proportions of powders used in four sample mixtures (weighing 10 grams) are given in Table 1. Gram weight of powders was calculated according to the formula given in Eq. 1.

$$
\mathrm{C}_{\mathrm{n}}=\left(\mathrm{C}_{\mathrm{n}}^{\prime} \cdot \mathrm{A}_{\mathrm{n}}\right) /\left[\left(\mathrm{C}_{1}^{\prime} \cdot \mathrm{A}_{1}\right)+\left(\mathrm{C}_{2}^{\prime} \cdot \mathrm{A}_{2}\right)+\left(\mathrm{C}_{3}^{\prime} \cdot \mathrm{A}_{3}\right)\right] \times 100
$$

Where,

$\mathrm{C}_{\mathrm{n}}=$ Weight $\%$ of powders of component $\mathrm{n}$

$\mathrm{C}^{\prime}{ }_{\mathrm{n}}=$ Atom $\%$ of powders of component $\mathrm{n}$

$\mathrm{A}=$ Atomic weight

$\mathrm{n}=1,2,3$ (represents $\mathrm{Al}$, Ti and $\mathrm{SiC}$ respectively)

After drying, powder mixtures were compressed for $3 \mathrm{~min}$ in a hydraulic press (Specac Hydraulic Press) under a pressure of $70 \mathrm{MPa}$. using a steel die having internal diameter of $10 \mathrm{~mm}$. Green compacts were then sintered at $620{ }^{\circ} \mathrm{C}$ in a tube furnace (KJ-1600VF, Kejia Furnace Company, China) with heating rate of $5{ }^{\circ} \mathrm{C} / \mathrm{min}$ under argon atmosphere. Holding time at desired sintering temperature was $4 \mathrm{hr}$, followed by cooling. After that, annealing of sintered pellets in furnace (ENTEC Chamber Furnace) was performed at $160{ }^{\circ} \mathrm{C}$ for $7 \mathrm{hr}$. Fig. 2 represents the schematic of fabrication process of Al-Ti based alloy.

Table 1 Sample mixtures prepared for study.

\begin{tabular}{|c|l|c|c|c|}
\hline No. & Sample mixture[atom \%] & Al[g] & Ti[g] & SiC $[\mathbf{g}]$ \\
\hline 1 & Pure Al & 10 & - & - \\
\hline 2 & Al-5Ti & 9.15 & 0.85 & - \\
\hline 3 & Al-10Ti & 8.35 & 1.65 & - \\
\hline 4 & Al-10Ti-2SiC & 8.09 & 1.64 & 0.27 \\
\hline
\end{tabular}




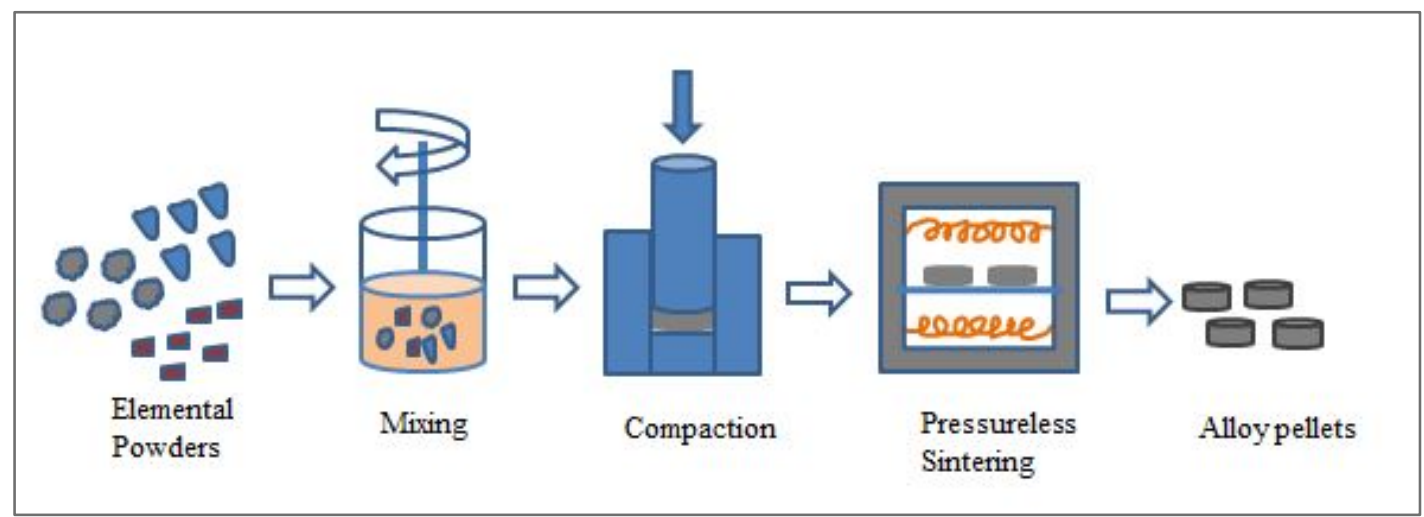

Fig. 2 Schematic of fabrication of Al-Ti based alloy.

Characterization. Average particle sizes of powders were measured as 70, 100 and $25 \mu \mathrm{m}$ for $\mathrm{Al}$, $\mathrm{Ti}$ and $\mathrm{SiC}$, respectively. Fig. 3 and Table 2 present powder morphologies used in this study. Sintered samples were prepared for evaluation according to standard metallographic procedures. Grinding was done using SiC emery papers of grade 320, 600, 800, 1000, 1200, 1500 and 2000 rotating at 100-300 rpm. Alumina paste was used for polishing. Keller's reagent $(190 \mathrm{ml}$ distilled water, $5 \mathrm{ml} \mathrm{HNO}, 2 \mathrm{ml} \mathrm{HF}$, and $3 \mathrm{ml} \mathrm{HCl}$ ) was used as an etchant.
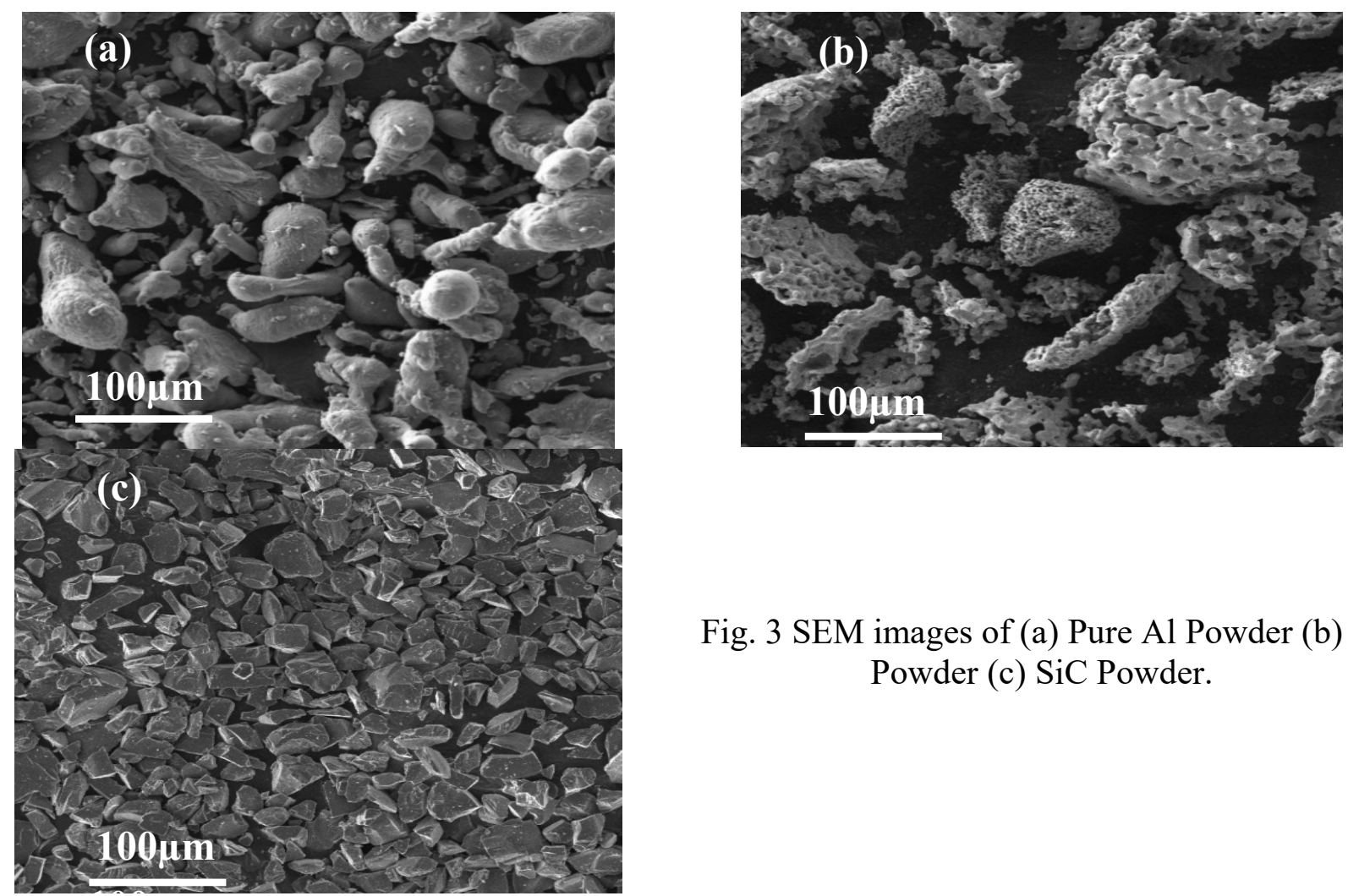

Table 2 Powders' Morphology.

\begin{tabular}{|c|c|}
\hline Powders & Particle Shape \\
\hline $\mathrm{Al}$ & Dense, irregular \\
\hline $\mathrm{Ti}$ & Porous, irregular \\
\hline $\mathrm{SiC}$ & Dense, irregular \\
\hline
\end{tabular}

Scanning electron microscopy (SEM) in BSE mode along with Energy Dispersive X-ray spectroscopy (EDS) was employed for surface analysis, microstructural and elemental examination. Vickers indentation test (Fujitsu HmV-G, Shimadzu Corporation) was carried out under test load of 
$500 \mathrm{~g}(4.903 \mathrm{~N})$. To obtain an average hardness value, five to seven values were taken for each specimen under same test load.

\section{Results and Discussion}

Density. Table 3 represents the density values of all test samples. Theoretical densities were calculated using rule of mixtures. Densification was calculated according to the formula given in Eq.2.

Densification $=$ Experimental density $/$ Theoretical Density $\mathrm{x} 100$

With 5 at.\% addition of Ti in Al, initially a decrease in density was observed. Overall, reasonable densification was found in all specimens.

Table 3 Theoretical, experimental density and densification measurements of sintered samples.

\begin{tabular}{|l|c|c|c|}
\hline \multicolumn{1}{|c|}{ Test Samples } & $\begin{array}{c}\text { Theoretical } \\
\text { Density }\left[\mathbf{g} / \mathbf{c m}^{\mathbf{3}} \text { ] }\right.\end{array}$ & $\begin{array}{c}\text { Experimental } \\
\text { Density }\left[\mathbf{g} / \mathbf{c m}^{\mathbf{3}}\right]\end{array}$ & Densification[\%] \\
\hline Pure $\mathrm{Al}$ & 2.7 & 2.60 & 96 \\
\hline $\mathrm{A} 1+5 \% \mathrm{Ti}$ & 2.79 & 2.50 & 90 \\
\hline $\mathrm{A} 1+10 \% \mathrm{Ti}$ & 2.88 & 2.66 & 92 \\
\hline $\mathrm{A} 1+10 \% \mathrm{Ti}+2 \% \mathrm{SiC}$ & 2.89 & 2.69 & 93 \\
\hline
\end{tabular}

Microstructure. Fig. 4 shows SEM-EDS analysis of samples after sintering.
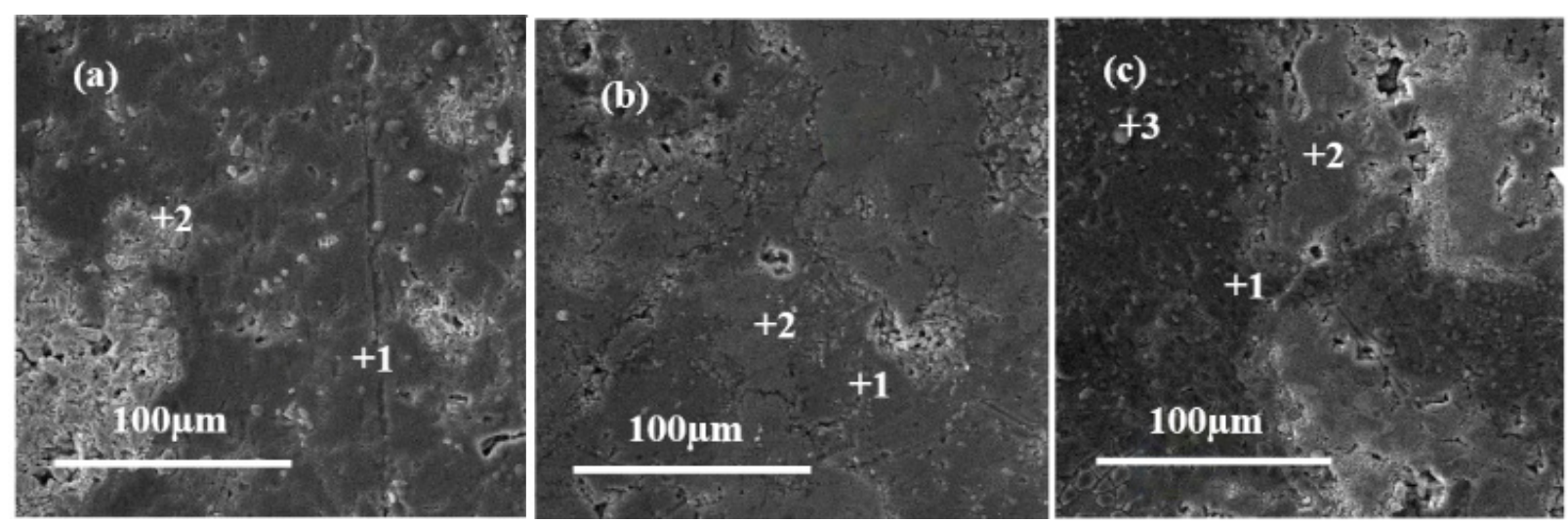

Fig. 4 SEM-EDS of sintered samples (a) Al+5 at.\%Ti (b) Al+10 at.\%Ti

(c) $\mathrm{Al}+10$ at. $\% \mathrm{Ti}+2$ at $\% \mathrm{SiC}$.

SEM micrographs show a contrast of dark and light gray regions. In EDS analysis (Table 4) dark regions were detected as pure $\mathrm{Al}$ and light regions showed compositions which corresponded to intermetallic phase $\mathrm{TiAl}_{3}$.

Table 4 The EDS analysis of marked region in Fig. 4.

\begin{tabular}{|c|c|c|c|c|c|c|}
\hline \multirow{2}{*}{ Figure 4} & \multirow{2}{*}{$\begin{array}{l}\text { Marked } \\
\text { region }\end{array}$} & \multicolumn{4}{|c|}{ Atomic \% } & \multirow{2}{*}{ Phase } \\
\hline & & Al & $\mathbf{T i}$ & $\mathbf{S i}$ & C & \\
\hline (a) & 1 & 100.00 & - & - & - & $\mathrm{Al}$ \\
\hline (a) & 2 & 74.86 & 25.14 & - & - & $\mathrm{TiAl}_{3}$ \\
\hline (b) & 1 & 100.00 & - & - & - & $\mathrm{Al}$ \\
\hline (b) & 2 & 72.21 & 27.79 & - & - & $\mathrm{TiAl}_{3}$ \\
\hline (c) & 1 & 100.00 & - & - & - & $\mathrm{Al}$ \\
\hline (c) & 2 & 75.41 & 24.59 & - & - & $\mathrm{TiAl}_{3}$ \\
\hline (c) & 3 & 3.83 & 0.07 & 44.74 & 51.36 & $\mathrm{SiC}$ \\
\hline
\end{tabular}


Hardness. Fig. 5 shows a plot of hardness values. Average hardness value of pure Al was found as $19 \mathrm{HV}$ which is in agreement with reported data [16]. With addition of 5 at.\% $\mathrm{Ti}$ in $\mathrm{Al}$, little increment in Vickers hardness from 19 to $22 \mathrm{HV}$ was observed. This could be attributed to the fact that only a small amount of intermetallic based alloy was formed. Further addition of Ti increased the hardness value up to $27 \mathrm{HV}$.

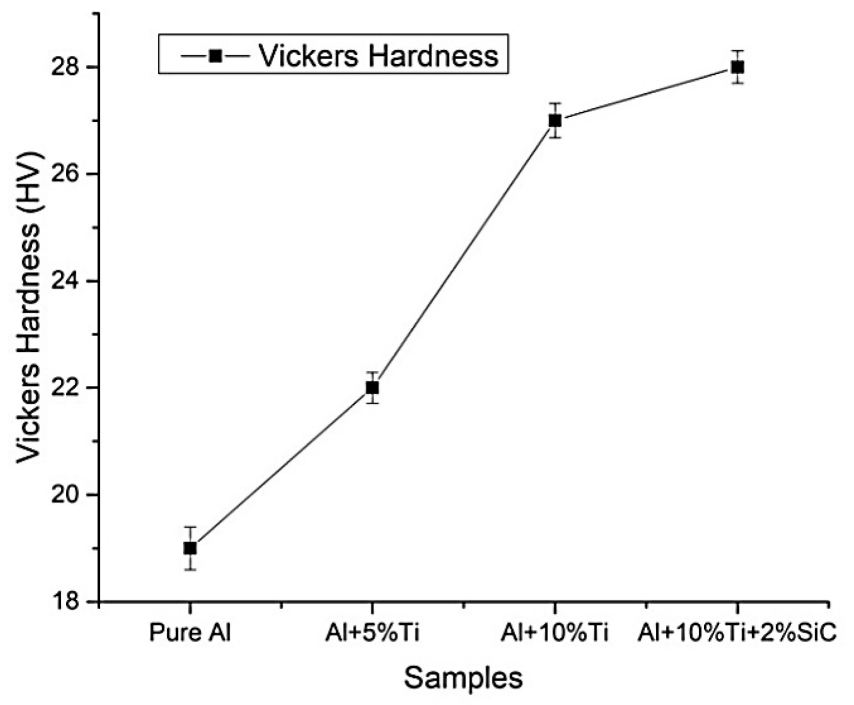

Fig. 5 Vickers Hardness of Pure Al, $\mathrm{Al}+5 \% \mathrm{Ti}, \mathrm{Al}+10 \% \mathrm{Ti} \& \mathrm{Al}+10 \% \mathrm{Ti}+2 \% \mathrm{SiC}$ sintered samples.

A very small ceramic reinforcement amount i.e. 2 at.\% of $\mathrm{SiC}$ further enhanced the hardness up to $28 \mathrm{HV}$. It can be inferred that further addition of reinforcement can enhance the hardness. As the phase diagram [Fig. 1] depicts, Ti has limited solid solubility in $\mathrm{Al}(<0.7$ at.\%) so solid solution strengthening has little effect on hardness of these specimens. The strengthening in this composition range (i.e. 5-10 at.\% $\mathrm{Ti}$ in $\mathrm{Al}$ ) is a result of dispersion of intermetallic phase in $\mathrm{Al}$ matrix which in turn increase the hardness. Dispersed phase in this alloy is $\mathrm{TiAl}_{3}$ which generate strain fields [17] in the Al matrix thus increasing the hardness.

\section{Summary}

Four test samples were prepared using powder metallurgy route. SEM shows the microstructure of alloy formed in Al-Ti system. Through EDS analysis, fabrication of some intermetallic phase in the alloy is observed. Specimens displayed a gradual increment in hardness with addition of 5-10 at.\% $\mathrm{Ti}$ and a higher value for ceramic reinforcement $\mathrm{SiC}$. Reasonable densification was found in all test samples. These results verify that the alloy produced in the Al-Ti system provides better mechanical aspects (i.e. Hardness) with lower densities so these alloys are a good option to replace heavier alloys for light weight and aerospace related applications.

\section{Acknowledgements}

Authors would like to thank Higher Education Commission (HEC) Pakistan for financial support under start-up and NRPU research grants. We are especially grateful to the department head Dr. Ibrahim Qazi and all the faculty members of Materials Sciences \& Engineering Department at the Institute of Space Technology. We would like to thank PhD student Mr. Mehmood Khan for his support, Metallography Lab attendant Muhammad Ayub for his generous guidance in lab work throughout the project, SEM lab In-charge Tahir Mehmood, Ceramics lab In-charge Sikandar Aziz and Muhammad Ibrahim for assisting in Hardness testing and particle size analysis. 


\section{References}

[1] V.A.R. Henriques, P.P.d. Campos, C.A.A. Cairo, J.C. Bressiani, Production of titanium alloys for advanced aerospace systems by powder metallurgy, Mater. Res., 8 (2005) 443-446.

[2] D. Batalu, G. Cosmeleata, A. Aloman, Critical analysis of the Ti-Al phase diagrams, UPD Sci. Bull., 68 (2006) 7.

[3] V. Kevorkijan, S. Davor, Pressureless sintering and characterization of $\mathrm{B}_{4} \mathrm{C}, \mathrm{TiC}$ and $\mathrm{TiB}_{2}$ particle reinforced $\mathrm{TiAl}_{3}$ matrix composites, Mater. Technol., 43 (2009) 123-128.

[4] M.E. Kassner, Fundamentals of creep in metals and alloys, Butterworth-Heinemann, 2015.

[5] K. Zhang, Z. Li, W. Gao, Hot corrosion behaviour of Ti-Al based intermetallics, Mater. Lett., 57 (2002) 834-843.

[6] R. Patterson, P. Martin, B. Damkroger, L. Christodoulou, Titanium aluminide: electron beam weldability, Weld. J., 69 (1990) 39-44.

[7] K.B. Kothari, Manufacturing Techniques for Titanium Aluminide Based Alloys and Metal Matrix Composites, University of Maryland, College Park, 2010.

[8] J. Lapin, TiAl-based alloys: Present status and future perspectives, in: Conference proceedings Metal, 19 (2009) 209-215.

[9] N. Lin, J. Zou, M. Li, J. Guo, Y. Ma, Z. Wang, Z. Wang, X. Liu, B. Tang, Review on improvements in surface performance of TiAl-based alloys by double glow plasma surface alloying technology, Rev. Adv. Mater. Sci., 44 (2016).

[10] M. Thomas, M.-P. Bacos, Processing and characterization of TiAl-based alloys: Towards an industrial scale, Aerosp. Lab., 3 (2011) p. 1-11.

[11] T. Klein, H. Clemens, S. Mayer, Advancement of compositional and microstructural design of intermetallic $\gamma$-TiAl based alloys determined by atom probe tomography, Mater., 9 (2016) 755 .

[12] V. Amigó, F. Romero, C. Da Costa, M. Salvador, Titanium and aluminium composites materials reinforced by Ti-Al compounds.

[13] J. Yang, W.-S. Hwang, The preparation of TiAl-based intermetallics from elemental powders through a two-step pressureless sintering process, J. Mater. Eng. Perfor., 7 (1998) 385-392.

[14] L. Hsiung, Powder metallurgy tial alloys: microstructures and properties, in: Lawrence Livermore National Laboratory (LLNL), Livermore, CA, 2006.

[15] H. Baker, H. Okamoto, Alloy Phase Diagrams, ASM Handbook, Vol. 3, ASM International, Materials Park, OH, 1992.

[16] M. Khan, M. Zulfaqar, F. Ali, T. Subhani, Hybrid aluminium matrix composites containing boron carbide and quasicrystals: manufacturing and characterisation, Mater. Sci. Technol., 33 (2017) 1955-1963.

[17] A.P. Mouritz, Introduction to aerospace materials, Elsevier, 2012. 